\title{
SuperPython: experimento de ensino de programação para crianças e adolescentes
}

\author{
Verônica Sakane Matias, Érica Calil Nogueira, Carlo Emmanuel Tolla de Oliveira \\ e Ewerton Fernandes Monteiro
}

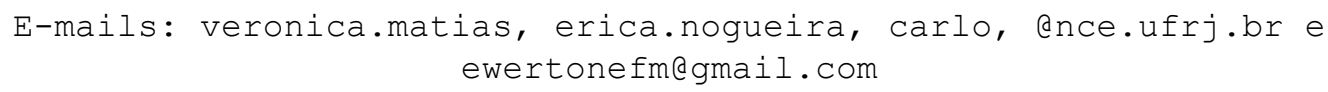

\begin{abstract}
This paper describes an inclusive educational method for children and adolescents that leads them towards their citizenship and learning in spite of the difficulties they might face: be it social, cognitive, behavioral, regional or regarding any specific content to be learned. The educational model will be presented as applied in the teaching of contents that are considered advanced for any age: programming language.
\end{abstract}

Resumo. Este artigo descreve um método de educação inclusiva para crianças e adolescentes que os direcionam à cidadania e aprendizado independente das dificuldades que encontrem: sejam sociais, cognitivas, comportamentais, regionais ou ligadas ao conteúdo a ser aprendido. O modelo educacional será apresentado como aplicado no ensino de conteúdo considerado avançado para qualquer idade: linguagem de programação.

\section{Introdução}

O modelo educacional aplicado atualmente nas escolas não está sendo capaz de suprir a necessidade das crianças de atingir seu real potencial de aprendizado. Este modelo tradicional baseia-se em leitura e exercícios repetitivos pré-definidos que muitas vezes incentivam a memorização de informações e não o aprendizado do conteúdo. Além disso, as atividades escolares mantêm o mesmo padrão, tornando-se monótonas. Para o estudante, isso resulta em desmotivação e até mesmo baixa autoestima, acarretando no não desenvolvimento de seu real potencial.

\section{Objetivo}

Aplicação de um método que ofereça às crianças e jovens acesso à educação de modo inclusivo, permitindo criar nas escolas um ambiente agradável onde alunos cooperem e comuniquem-se entre si e com os professores, de forma que todo aluno se interesse e participe independentemente da dificuldade e que não haja segregação. Em uma mesma turma poderão aprender, da mesma forma, estudantes com dificuldades cognitivas e superdotados, numa inclusão eficiente em que problemas regionais e sociais - como áreas conflagradas e a segregação de disciplinas por gênero - não afetem a educação de aluno algum, promovendo a cidadania e possibilitando uma vida escolar saudável e divertida, que promove a autoconfiança e motiva o aprendizado. Será ensinado um conteúdo moderno, considerado importante para as novas gerações: a linguagem de programação. 
V Congresso Brasileiro de Informática na Educação (CBIE 2016)

Anais dos Workshops do V Congresso Brasileiro de Informática na Educação (CBIE 2016)

\section{Problema}

O método educacional baseado em nivelamento por notas e provas, frequentemente utilizado, muitas vezes leva os estudantes a apenas memorizarem informações que logo serão esquecidas, no lugar do mais importante: o aprendizado de fato. Isso torna as aulas ineficientes, repetitivas e cansativas para o aluno. Soma-se a isso a relação aluno-professor tradicional, hierarquizada, com comunicação sem afinidade, excessivamente formal ou mesmo inexistente.

Os problemas estão com os professores! Se o professor é legal, a aula muda
totalmente, se o professor fala o mesmo papo que você, gosta das mesmas
coisas que você, fala a mesma coisa que a turma fala, brinca com a com turma,
fala para fazer trabalho em grupo, essas coisas nós adoramos na aula. Aquele
professor que não está nem aí, passa só dever de casa, dá a matéria, se a turma
ficar quieta fala que a matéria já está dada, o pessoal odeia.... Não é o lugar, o
local. (G., estudante. Depoimento coletado pelos autores e registrado em vídeo)

Na maioria das vezes, o professor se dirige ao aluno são apenas para emitir ordens e controlá-lo, impedindo-o de ficar à vontade e seguro para tirar dúvidas e/ou se interessar pela aula. São obrigados a acompanhar um nível imposto pelo professor, sendo mal vistos se não conseguem fazê-lo, e não são estimulados a tentar ultrapassá-lo. Quase não há atividades para praticar o conteúdo ensinado e nem que promovam a socialização entre os estudantes, acarretando a individualização e a indiferença com o próximo, dificultando a socialização e negando o desenvolvimento para a cidadania. Ou mesmo consequências piores, infelizmente comuns nas escolas e na infância das crianças, dentre estas o bullying. Com tais dificuldades encontradas pela maioria dos estudantes, estes consideram o ambiente escolar e o ato de estudar como algo negativo.

\section{Proposta}

A proposta é fazer do ambiente de sala de aula um lugar de diversão e não de obrigação, tratando-o como espaço mais informal e descontraído, construindo uma sala de aula em que professor e aluno não estejam na relação hierarquizada que é comumente vista nas escolas. A afinidade através de um convívio mais próximo do aluno, conversas informais e maior grau de afetividade fazem o aluno sentir-se mais confortável em relação ao professor e monitores. Junto a isto, o oferecimento de maior liberdade ao aluno, que, após terminar a atividade proposta em sala de aula, estará livre para seguir além com ajuda do professor e dos monitores, ou relaxar, por exemplo, com jogos em que o colega ao lado ou os monitores também participem. Esse processo já foi discutido em outro artigo da equipe, que trata mais detalhadamente dessas relações e do método utilizado:

O modelo lúdico aqui proposto é o jogo de fazer o jogo. A base da metodologia pedagógica é uma adaptação da base neurocientífica cognitiva que utiliza a técnica de grupos operativos (Pichon-Reviére, 1998) e elaboração dirigida (Seminário, 1987) com aplicação do Fio Condutor (Marques, 2009). O ensino baseado em problemas é o patamar inicial do Fio Condutor que se expande em um modelo de neuropedagogia computacional. Nesta pedagogia o computador 
é o paramediador onde ele é o próprio estímulo e desafio que encaminha o desenvolvimento do aprendizado ${ }^{1}$.

A organização da sala de aula consiste em o professor não se limitar a ficar à frente do quadro passando instruções, mas também junto aos monitores que ficam espalhados pela sala, sentados ou em pé, perto dos estudantes, a fim de auxiliá-los o mais rápido possível, conseguindo assim sanar de forma eficiente todas as dúvidas sem que estas se percam porque a criança não conseguiu falar ou não se sentiu à vontade para interromper a explicação. Todos os estudantes estão organizados em duplas, cada uma em um computador, sempre que possível com níveis diferentes de conteúdo já adquirido, o que estimula a cooperação entre os estudantes na hora de programar, pois o mais experiente ajuda o iniciante nos pontos em que este apresenta dificuldade. É bom ressaltar que essas duplas não se mantêm fixas, ajudando os estudantes a interagirem com toda a turma e favorecendo um rodízio onde aquele que antes era o mais experiente pode achar-se na posição de iniciante em outra dupla, aprendendo novas habilidades.

\section{Justificativa}

Um ambiente divertido é descontraído, livre de obrigações, onde todos se sentem à vontade e são amigos. Para que a sala de aula seja esse ambiente, o professor deve estabelecer uma relação informal com os estudantes, descontraída, amigável e de preferência não hierarquizada de forma que todos sintam-se à vontade para se comunicar, tirar dúvidas e felizes em realizar tarefas escolares com os professores. Ao tornar o estudo divertido, as crianças se mobilizam e aprendem. Aprendendo, elas sentem-se confiantes para se desafiarem a buscar mais conhecimentos.

\footnotetext{
Este sentimento de autoeficácia (Bandura, 1977) se transforma em um estímulo interno onde o estudante sente que tem a competência de ir adiante e construir algo que não havia tentado antes ${ }^{2}$.
}

Quando o conteúdo é oferecido com tarefas cooperativas e decisões são tomadas pelos próprios estudantes, o tempo de desenvolvimento do material se torna mais prazeroso e a atividade mais divertida, envolvente. Isso promove a comunicação entre os estudantes e a troca de conhecimentos. Essa interação também facilita a socialização e a cidadania entre os estudantes, impedindo a prática do bullying. É interessante utilizar nessas tarefas atividades que promovam a criatividade, de forma que trabalhem a ideia ensinada na disciplina, fortalecendo e incentivando os alunos a entenderem melhor o conteúdo e não se limitarem apenas ao que o professor ensinou.

... o maior êxito deste projeto está no fato de que toda essa atividade quebra barreiras e estimula uma das características humanas mais em falta no mundo: a criatividade. Dessa forma, os estudantes que utilizarem este método serão

1 OLIVEIRA, Carlo et al. Relação estudante-professor: Educação Baseada na Construção de Jogos. In: XXVI Simpósio Brasileiro de Informática na Educação, Maceió, 2015. p. 637-646.

2 ibid. 
V Congresso Brasileiro de Informática na Educação (CBIE 2016)

Anais dos Workshops do V Congresso Brasileiro de Informática na Educação (CBIE 2016)

pessoas mais conscientes de si e do mundo, e buscarão maneiras inovadoras de resolver os problemas da sociedade ${ }^{3}$.

Em busca de tornar o aprendizado lúdico, para as aulas de linguagem de programação foi escolhido trabalhar na criação de jogos. Além de ser uma das formas de lazer mais comum da sociedade em que estamos inseridos, há também a questão neurocientífica ${ }^{4}$ que aponta o lúdico como uma forte estrutura para a aprendizagem e o conjunto de possíveis utilizações dos processos de gameficação $o^{5}$ nas atividades propostas num ritmo metalinguístico ${ }^{6}$ onde se pode criar um jogo jogando ${ }^{7}$.

\section{Método}

As aulas são realizadas com a presença de um professor-mediador e de uma junta de monitores, de forma que os estudantes sempre tenham algum profissional disponível para esclarecer suas dúvidas. As disciplinas possuem três etapas para o aprendizado do conteúdo:

A primeira etapa consiste na união de todos os estudantes para um brainstorm. Todos manifestam suas ideias, passando-as para um papel em estilo post-it, como na FIGURA 1. Nesta etapa e na seguinte, não utilizamos a sala de informática, mas sim uma sala que tenha mesas livres. Estas são unidas de forma a posicionar os estudantes em um círculo, permitindo que tenham melhor contato uns com os outros. Na segunda etapa, os estudantes criam cenários, personagens e outras ideias complementares. Usamos como ferramenta para apoiar esse processo O Jogo do Mundo, assim os estudantes podem criar a maquete do cenário permitindo uma melhor visualização deste e de outras ideias.

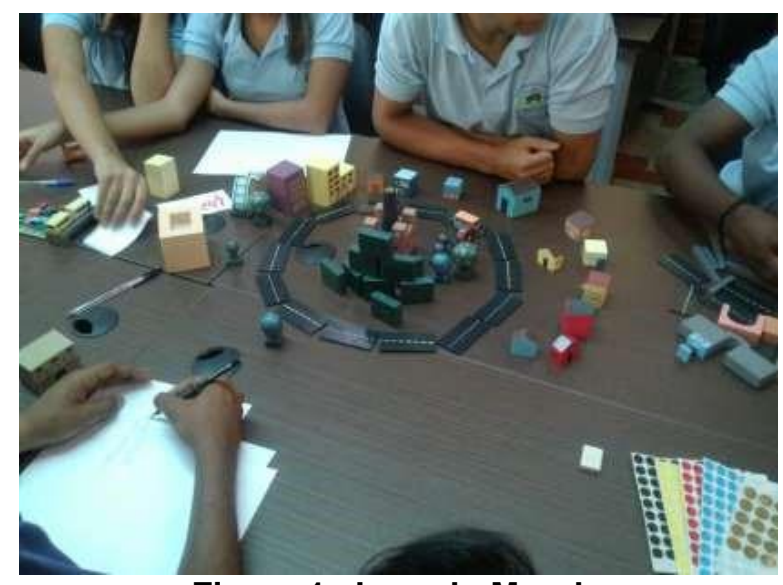

Figura 1. Jogo do Mundo

$\mathrm{Na}$ terceira etapa, os estudantes montam a ideia principal baseada nas etapas anteriores, e concluindo isso, começam a aprender a linguagem de programação Python em paralelo ao desenvolvimento do enredo. Na FIGURA 2, vemos um programa

ibid.

Marques, 2009.

Bunchball, 2010.

Oliveira, 2015.

ibid. 
V Congresso Brasileiro de Informática na Educação (CBIE 2016)

Anais dos Workshops do V Congresso Brasileiro de Informática na Educação (CBIE 2016)

desenvolvido por um aluno com base em seu próprio roteiro, um dos primeiros programas a serem feitos no projeto. Diferente das outras etapas, nesta os estudantes trabalham em dupla, sendo um membro experiente e o outro um novato. Desse modo, o novato poderá tirar suas dúvidas com o experiente e o experiente será desafiado a responder, explicar e rever o conteúdo com o novato.

É também dada maior liberdade aos estudantes: como são utilizados computadores nas aulas, aos estudantes não é proibido utilizar a internet para assistir a vídeos, jogar jogos e outros afins lícitos para suas faixas etárias. A iniciativa de participar da aula vem dos próprios estudantes.

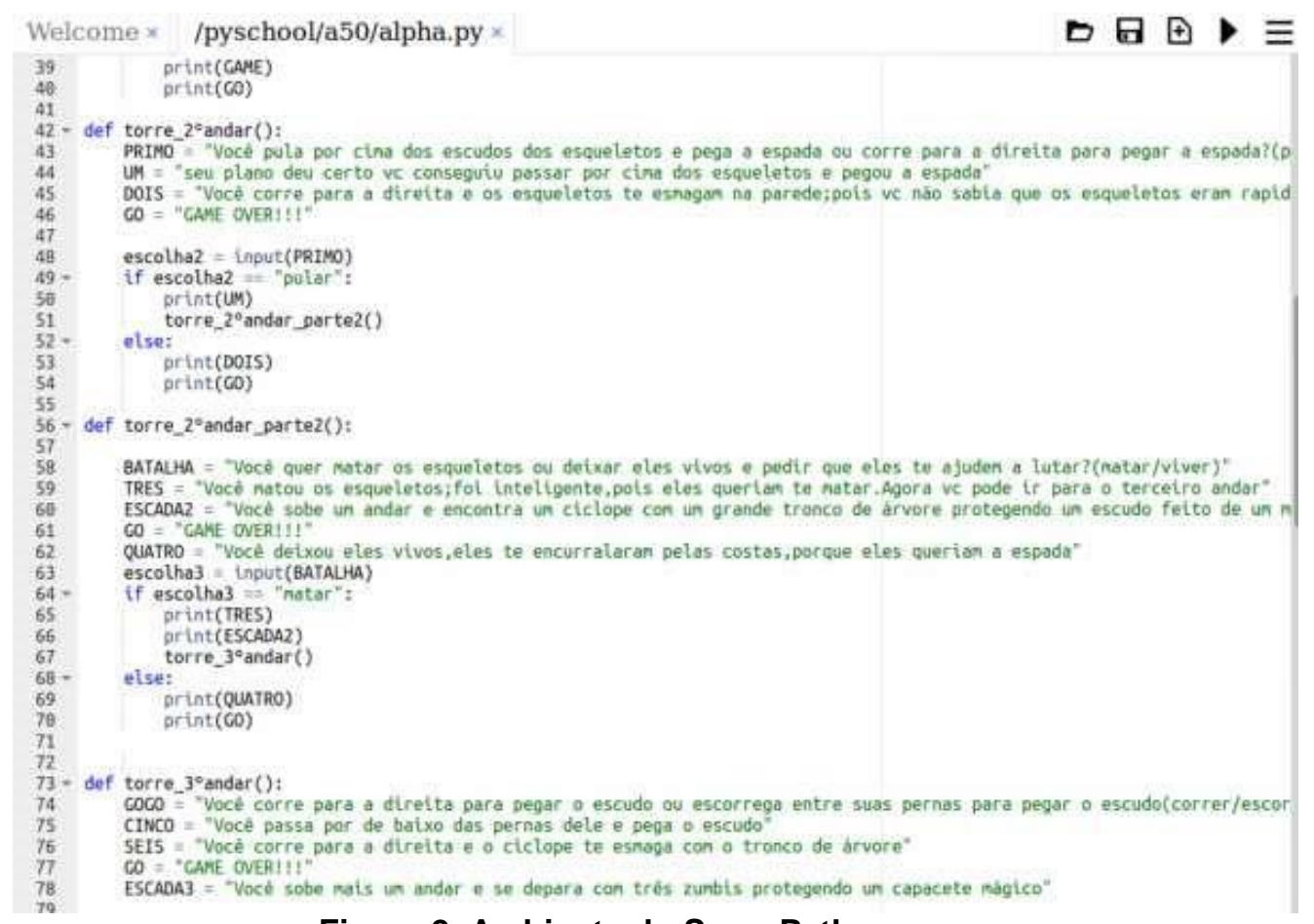

Figura 2. Ambiente do SuperPython

O método foi aplicado no total em 16 projetos com estudantes de diversos perfis. No exemplo do desenvolvimento do jogo "O Museu da Geodiversidade", a aula teve a participação de estudantes de três regiões diferentes — CETEP de Paracambi (cidade da Região Metropolitana), escola de Ensino Fundamental José de Alencar (Zona Sul) e escola de Ensino Fundamental Daniel Pizza (Zona Oeste) —, idades diferentes (7 a 17 anos) e situações diferentes: estudantes de ensino técnico em informática, com altashabilidades ${ }^{8}$ e que vivem em regiões conflagradas, respectivamente. Na FIGURA 3 vemos tais estudantes, e na FIGURA 4, o jogo desenvolvido por um aluno. "O Jogo da Cidade" foi aplicado em estudantes da graduação da UFRJ. Já "SuPyGirls" é um projeto com estudantes de perfis semelhantes àqueles envolvidos com "O Museu da Geodiversidade", mas exclusivamente do gênero feminino. Todos tiveram resultados positivos, além de aprenderem um conteúdo considerado complexo para crianças e jovens. 
V Congresso Brasileiro de Informática na Educação (CBIE 2016)

Anais dos Workshops do V Congresso Brasileiro de Informática na Educação (CBIE 2016)

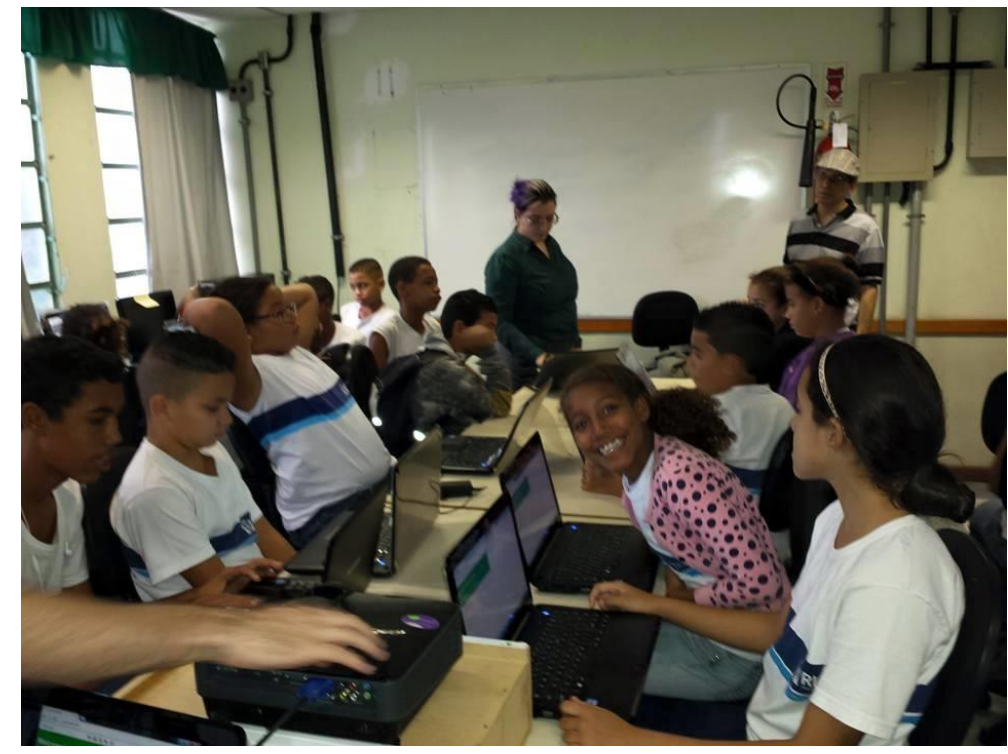

Figura 3. Estudantes do SuperPython

\section{Modelo Inclusivo}

Em todos os projetos foi verificada a inclusão de todos os estudantes de diversas maneiras. Estudantes com dificuldades de socialização - como os autistas conseguiram uma melhora na comunicação com os colegas; estudantes que moravam em áreas conflagradas e motivavam muitas queixas de professores por problemas de comportamento tiveram melhoras; alunas criadas em ambientes que desestimulavam seu envolvimento com disciplinas da área de ciências exatas devido ao gênero se sentiram capazes de aprender qualquer assunto. Em suma, o método integra todos os estudantes de distintos níveis de conhecimentos e habilidades em todos os momentos e etapas do trabalho. Proporcionando o crescimento do conhecimento sem o detrimento das competências individuais de cada aluno.

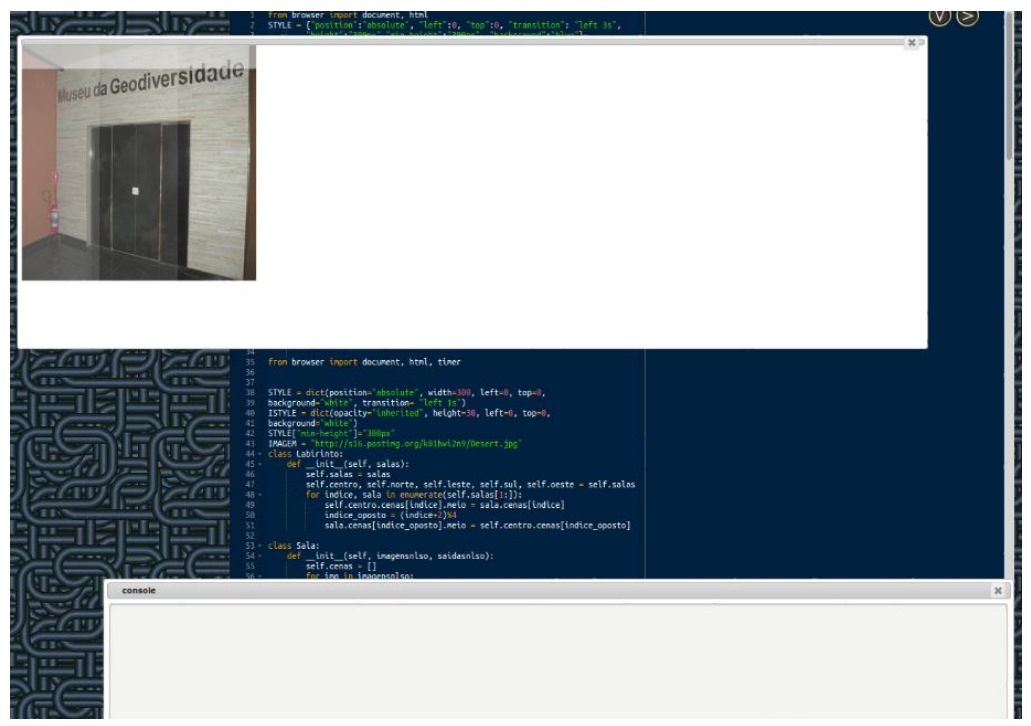

Figura 4. Jogo do Museu da Geodiversidade 
V Congresso Brasileiro de Informática na Educação (CBIE 2016)

Anais dos Workshops do V Congresso Brasileiro de Informática na Educação (CBIE 2016)

\section{Conclusão}

Este modelo tem mostrado um significativo resultado positivo no comportamento e rendimento dos estudantes. Crianças com diversas dificuldades de inclusão à educação conseguiram se beneficiar e aprender. O método foi aplicado desde crianças de ensino fundamental e seus respectivos professores até estudantes de graduação. Foi constatado que, independentemente da idade ou nível de conhecimento, o modelo inclusivo constitui uma poderosa ferramenta para a inclusão social e o desenvolvimento pessoal. O progresso foi acompanhado por professores das respectivas escolas e pais dos estudantes, e observado pelos próprios estudantes.

\section{Referências Bibliográficas}

MENDONÇA, A. et al. Uma proposta de ensino de linguagem programação de computadores neuropedagógica. In: XX Simpósio Brasileiro de Informática na Educação, 2009. Sociedade Brasileira de Computação. Porto Alegre, 2009.

PEREIRA, L. F. D. et al. Ateliê de Objetos de Aprendizagem: uma metodologia para o Ensino de Computação em Cursos Técnicos. Workshop de Educação Em Computação, Belo Horizonte. Rio de Janeiro-RJ-Brazil (2010).

OLIVEIRA, Carlo et al. Relação estudante-professor: Educação Baseada na Construção de Jogos. In: XXVI Simpósio Brasileiro de Informática na Educação, Maceió, 2015. p. 637-646.

BANDURA, A. (1977). Self-efficacy: Toward a Unifying Theory of Behavioral Change. Psychological Review 84 (2): 191-215.

Bunchball, Inc. Gamification 101: An introduction to the use of game dynamics to influence behavior. 2010. Disponível em:

<www.bunchball.com/sites/default/files/downloads/gamification101.pdf> Acesso em: dez. 2015.

EARNEY, B. Brython-in-the-classroom. Disponível em: <https://github.com/brython-dev/brython-in-the-classroom> Acesso em: dez. 2015.

FREIRE, Paulo. Pedagogia do Oprimido. 42 ed. Rio de Janeiro: Paz e Terra, 2005.

MARQUES, C. V. M. et al. Uma abordagem meta-cognitiva na construção coletiva do conhecimento. Rio de Janeiro: NCE/UFRJ, 2009.

. Neuropedagogia e Informática I: A Revolução Cognitiva - um estudo sobre a teoria de Franco Lo Presti Seminério. Rio de Janeiro: NCE/UFRJ,2009.

QUENTEL, Pierre. Brython. Disponível em: <http://brython.info> Acesso em dezembro. 
V Congresso Brasileiro de Informática na Educação (CBIE 2016)

Anais dos Workshops do V Congresso Brasileiro de Informática na Educação (CBIE 2016)

SEMINÉRIO, Franco Lo Presti. Elaboração dirigida: um caminho para o desenvolvimento metaprocessual da cognição humana. Rio de Janeiro: FGV; ISOP, 1987.

SILVA, V. S. R. et al. STOP DISASTERS: SERIOUS GAMES WITH ELEMENTARY SCHOOL STUDENTS IN RIO DE JANEIRO. In: 8th International Technology, Education and Development Conference, 2014, Valencia, Spain. INTED2014 Proceedings. UK: Thomson Reuters. v. 1, p. 1648-1659, 2014.

LEMOS, M. K. et al. Fio Condutor Microgenético: uma metodologia para a mediação metacognitiva em jogos computacionais. Revista Brasileira de Informática na Educação, v. 22, p. 1, 2014. 